\title{
Radiative forcing and feedback by forests in warm climates - a sensitivity study
}

\author{
Ulrike Port $^{1}$, Martin Claussen ${ }^{1,2}$, and Victor Brovkin ${ }^{1}$ \\ ${ }^{1}$ Max Planck Institute for Meteorology, 20146 Hamburg, Germany \\ ${ }^{2}$ Meteorological Institute, University of Hamburg, 20146 Hamburg, Germany \\ Correspondence to: Ulrike Port (ulrike.port@mpimet.mpg.de)
}

Received: 20 November 2015 - Published in Earth Syst. Dynam. Discuss.: 14 December 2015

Revised: 23 April 2016 - Accepted: 22 May 2016 - Published: 6 July 2016

\begin{abstract}
We evaluate the radiative forcing of forests and the feedbacks triggered by forests in a warm, basically ice-free climate and in a cool climate with permanent high-latitude ice cover using the Max Planck Institute for Meteorology Earth System Model. As a paradigm for a warm climate, we choose the early Eocene, some 54 to 52 million years ago, and for the cool climate, the pre-industrial climate, respectively. To isolate firstorder effects, we compare idealised simulations in which all continents are covered either by dense forests or by deserts with either bright or dark soil. In comparison with desert continents covered by bright soil, forested continents warm the planet for the early Eocene climate and for pre-industrial conditions. The warming can be attributed to different feedback processes, though. The lapse-rate and water-vapour feedback is stronger for the early Eocene climate than for the pre-industrial climate, but strong and negative cloud-related feedbacks nearly outweigh the positive lapse-rate and water-vapour feedback for the early Eocene climate. Subsequently, global mean warming by forests is weaker for the early Eocene climate than for pre-industrial conditions. Sea-ice related feedbacks are weak for the almost ice-free climate of the early Eocene, thereby leading to a weaker high-latitude warming by forests than for pre-industrial conditions. When the land is covered with dark soils, and hence, albedo differences between forests and soil are small, forests cool the early Eocene climate more than the preindustrial climate because the lapse-rate and water-vapour feedbacks are stronger for the early Eocene climate. Cloud-related feedbacks are equally strong in both climates. We conclude that radiative forcing by forests varies little with the climate state, while most subsequent feedbacks depend on the climate state.
\end{abstract}

\section{Introduction}

In present-day climate, forests tend to warm the high latitudes by masking the bright snow cover leading to a lower surface albedo than with bare soil or grass (Bonan, 1992; Betts and Ball, 1997; Bonan, 2008), and this warming can be amplified by the sea-ice albedo feedback (Claussen et al., 2001; Fraedrich et al., 2005; Brovkin et al., 2009). In the tropics, forests tend to cool the climate by enhancing transpiration and evaporation which leads to an increased cloud cover and a higher planetary albedo. The enhanced transpiration and evaporation by trees increase the latent heat flux resulting in further cooling (Bathiany et al., 2010). In our study, we explore the question whether these biogeophysi- cal effects of forests remain the same amplitude in a much warmer, ice-free climate. Instead of prescribing an artificially ice-free pre-industrial climate, we choose a palaeo-climate set-up.

Using the GENESIS climate model with a mixedlayer ocean, Otto-Bliesner and Upchurch (1997) investigate the impact of vegetation on the late Cretaceous climate (66 million years ago). Similar to the studies on present-day climate, they find that trees warm the late-Cretaceous high latitudes relative to bare soil by masking the snow cover and triggering the ice-albedo feedback. Also for the EoceneOligocene Transition, the simulations by Liakka et al. (2014) suggest that forests strongly warm Antarctica by masking the snow cover. The interaction of vegetation with the snow 
and ice cover appears to be strong in the studies by OttoBliesner and Upchurch (1997) and Liakka et al. (2014), because substantial snow and sea-ice coverage occurs in winter and spring in their simulations. In a climate that was presumably warmer than the late Cretaceous or the Eocene Oligocene Transition and nearly free of ice, the snow masking effect and the ice albedo feedback would vanish leading to a considerably different biogeophysical effect by vegetation than in the present-day climate. Alkama et al. (2012) analyse the impact of global desertification in present-day climate, in the cold climate of the last glacial maximum, and in a warm climate caused by an increase in greenhouse gas concentrations. They find that the reduction of upward latent heat fluxes dominates the prevailing signal in terms of surface energy budget. In their simulations, desertification yields a similar temperature response for all climate states in regions south of $20^{\circ} \mathrm{N}$. At high latitudes, the effect of desertification differs because of the difference in snow albedo feedback.

Here, we choose the early Eocene climate (54-52 Ma) which was a warm, presumably nearly ice-free climate. Tropical temperatures were 5 to $6 \mathrm{~K}$ higher than today (Pearson et al., 2007), and polar temperatures were above the freezing point during most time of the year leading to almost icefree poles (Hutchison, 1982; Markwick, 1994; Ivany et al., 2006; Zachos et al., 1992). In agreement with proxy data (Zachos et al., 1992), no permanent sea ice occurs for the early Eocene climate simulations by Heinemann et al. (2009).

In their modelling studies, Sewall et al. (2000) and Loptson et al. (2014) assess the sensitivity of the early Eocene climate to vegetation. Sewall et al. (2000) find that vegetation cools regional climate in coastal Australia, central South America, central North America, and in south-central Africa. They trace the cooling back to an enhanced latent heat flux by vegetation leading to an increased cloud cover. The dynamic vegetation used by Loptson et al. (2014) warms the global mean Eocene climate relative to a homogeneous shrub cover by reducing surface albedo and enhancing humidity leading to a stronger greenhouse effect. Both studies consider the early Eocene climate only, while the studies mentioned at the beginning focus on the biogeophysical effect of vegetation in present-day climate. Hence, a consistent quantitative comparison of the biogeophysical effect of vegetation in the warm, nearly ice-free and snow-free climate of the early Eocene and in the pre-industrial interglacial climate is not possible. To close this gap, we compare the biogeophysical effect of vegetation in both these climates using a consistent experimental set-up for both climates.

To disentangle direct biogeophysical effects and triggered feedbacks, we use the linear regression approach proposed by Gregory et al. (2004). This approach yields an estimate of the radiative forcing by forests and of the subsequent climate feedbacks. We expect that radiative forcing by forests depends on the soil albedo. To isolate the impact of soil albedo on the radiative forcing by forests, we specify different soil albedo. First, we choose a value of 0.1 for soil albedo which is about the albedo of volcanic rocks and granite bedrock (Warner, 2004). In this case, soil and vegetation have similarly low values of albedo. Second, we assume a homogeneous soil albedo of 0.4 , i.e. a value representative for bright soil, which has a much higher albedo than the forests have.

For the early Eocene climate and the pre-industrial climate, we prescribe an atmospheric $\mathrm{CO}_{2}$ concentration of 560 and $280 \mathrm{ppm}$, respectively. In other words, we neglect the $\mathrm{CO}_{2}$ uptake by forests and focus on the biogeophysical effect of forests.

\section{Model and experiments}

\section{$2.1 \mathrm{MPI}-\mathrm{ESM}$}

The MPI-ESM consists of the atmospheric general circulation model ECHAM6 (Stevens et al., 2013), the Max Planck Institute Ocean Model (MPIOM) (Jungclaus et al., 2013), the land surface scheme JSBACH (Reick et al., 2013), and the ocean biogeochemistry model HAMOCC (Ilyina et al., 2013). ECHAM6 and JSBACH run in a horizontal resolution of T31, which corresponds to approximately $3.75^{\circ} \times 3.75^{\circ}$. ECHAM6 considers 31 levels in the vertical up to $10 \mathrm{hPa}$. The ocean grid has a resolution of about $3^{\circ}$ and consists of 40 levels in depth.

The JSBACH model simulates fluxes of energy, water, momentum, and $\mathrm{CO}_{2}$ between the land surface and the atmosphere (Raddatz et al., 2007). To represent vegetation composition, land grid cells in JSBACH are divided into tiles (fractions). Those tiles are covered with several plant functional types or PFTs (trees, shrubs, and grasses), and two types of bare surface and seasonally bare soil and permanently bare ground, or desert (Brovkin et al., 2009; Reick et al., 2013). In the JSBACH model setup used in this study, the fraction of land surface covered with particular PFTs is prescribed and phenology (LAI) is kept constant throughout the season in order to simplify the analysis of interactions between land and atmosphere.

\subsection{Early Eocene set-up}

To simulate the early Eocene climate, we use the maps of orography and bathymetry by Bice and Marotzke (2001) which Heinemann et al. (2009) interpolated from the original resolution of $2^{\circ} \times 2^{\circ}$ to the model resolution of $3.75^{\circ} \times 3.75^{\circ}$. The orography map lacks information on sub-grid orography. Hence, ECHAM6 cannot parameterise sub-grid interactions of atmospheric flow with orography (Stevens et al., 2013), and so we switch off the module for sub-grid orographic drag and wave generation. The distribution of continents requires the shifting of the regular MPIOM 
Table 1. Boundary conditions for the early Eocene climate simulations and for pre-industrial conditions simulations.

\begin{tabular}{lll}
\hline & Pre-industrial & Early Eocene \\
\hline $\mathrm{CO}_{2}$ concentration & $280 \mathrm{ppm}$ & $560 \mathrm{ppm}$ \\
Methane & $0.8 \mathrm{ppm}$ & $0.8 \mathrm{ppm}$ \\
Nitrous oxide & $0.288 \mathrm{ppm}$ & $0.288 \mathrm{ppm}$ \\
Orbit & pre-industrial & pre-industrial \\
Bathymetry and orography & present-day & Bice and Marotzke (2001) \\
Ice sheets & pre-industrial & none \\
\hline
\end{tabular}

north pole of the ocean grid to Palaeo-Asia and the grid south pole to Palaeo-South America.

Following Heinemann et al. (2009), the atmospheric $\mathrm{CO}_{2}$ concentration is fixed to $560 \mathrm{ppm}$ (Table 1), which represents the lower limit of reconstructions (Zachos et al., 2001; Beerling and Royer, 2011). Estimates of other greenhouse gases, like methane and nitrous oxide, are absent for the early Eocene. Thus, we proceed as Heinemann et al. (2009) and prescribe pre-industrial values for methane and nitrous oxide for the early Eocene atmosphere (Table 1). We decide to use a pre-industrial orbit in our early Eocene simulations. This approach limits the differences between the early Eocene and the pre-industrial boundary conditions to the distribution of continents, the bathymetry, the appearance of ice sheets, and the atmospheric $\mathrm{CO}_{2}$ concentration (Table 1).

To achieve an initial equilibrium climate, we simulate the Eocene climate starting from the equilibrium climate by Heinemann et al. (2009). Like in their simulation, we assume a globally homogeneous savanna vegetation with a desert cover of $40 \%$, a tree cover of $24 \%$, and a grass cover of $36 \%$. After 300 years, near-surface temperature and upperlevel ocean temperatures are in equilibrium. Only in the deep ocean, a marginal temperature trend of some $0.04 \mathrm{~K}$ per 100 years remains.

To evaluate the equilibrium Eocene climate, which we use as initial state for all Eocene simulations, we compare the simulated climate against the marine and terrestrial temperature reconstructions used by Lunt et al. (2012) and Huber and Caballero (2011), respectively. Lunt et al. (2012) merge palaeotemperature estimates at the sea surface, near the sea surface, and in shallow inner-shelf bottom water based on oxygen isotope $\left(\delta^{18} \mathrm{O}\right)$ values, on Magnesium-Calcium ratios $(\mathrm{Mg} / \mathrm{Ca})$ derived from planktic foraminifera, and on $\mathrm{TEX}_{86}$. In all measurement sites, several methods have been applied to estimate temperature. Like Lunt et al. (2012), we use the average over all temperature estimates in one site. The compilation includes temperature reconstructions from just before the onset of the Paleocene-Eocene thermal maximum (PETM) ( 55 Ma) until the Early Eocene climatic optimum (EECO) ( 50-52 Ma). Temperature estimates of the PETM itself and of the EECO are excluded in our comparison to the simulated Eocene climate.

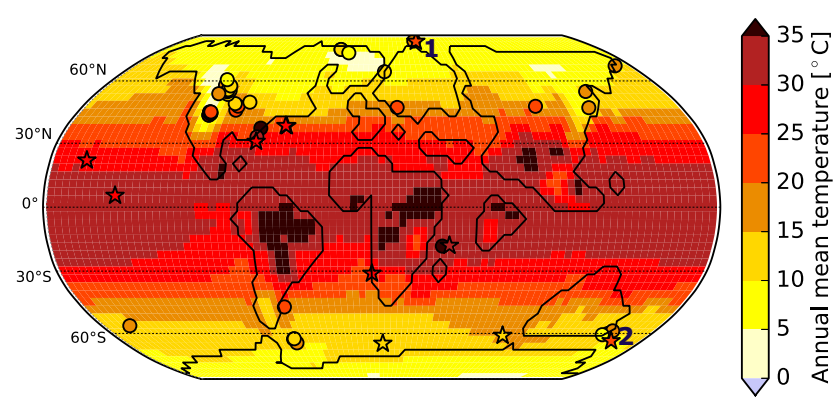

Figure 1. Annual mean $2 \mathrm{~m}$ temperature for the early Eocene simulation in shaded colours. Stars show reconstructed annual mean sea surface temperature (SST) and near-surface temperature of the early Eocene derived from $\delta^{18} \mathrm{O}, \mathrm{Mg} / \mathrm{Ca}$, and $\mathrm{TEX}_{86}$ (Lunt et al., 2012). Numbers 1 and 2 mark SST reconstructions by Sluijs et al. (2006) and Bijl (2009), respectively. Circles refer to terrestrial annual mean temperature estimates based on macrofloral and palynoflora assemblage data and from teeth, hydrogen isotopes, and oxygen isotopes (Huber and Caballero, 2011).

Huber and Caballero (2011) provide a compilation of annual mean temperature for the early Eocene based on terrestrial proxy data. Most temperature estimates in this compilation result from the analysis of macrofloral assemblage data using the Climate Leaf Analysis Multivariate Program (CLAMP) (Wolfe, 1995) and the leaf margin analysis (LMA; Wilf, 1997). Further, the data base includes temperature estimates based on teeth, hydrogen isotopes, oxygen isotopes, and palynoflora assemblage data.

The simulated annual mean temperatures show a good agreement with the temperature estimates in the tropics and subtropics (Fig. 1), while discrepancies appear in the mid- to high latitudes. In the mountainous terrain in North America, the temperature estimates vary over small distances because the altitude does. Our model fails to resolve the small-scale orography leading to a mismatch of simulated and reconstructed temperature.

In the northern high latitudes, terrestrial temperature reconstructions are 5 to $11 \mathrm{~K}$ higher than the simulated temperature. Especially, the marine temperature reconstruction by Sluijs et al. (2006) strongly exceeds the simulated annual mean temperature north of Greenland (Fig. 1). This SST estimate is based on $\mathrm{TEX}_{86}$, which likely has a bias to represent summer temperatures (Sluijs et al., 2006). Considering summer temperatures, our model produces a $5 \mathrm{~K}$ lower temperature than suggested by Sluijs et al. (2006).

In the southern high latitudes, the simulation agrees with marine and terrestrial temperature estimates. The only exception is the SST reconstruction by Bijl (2009) that suggests a temperature of $24^{\circ} \mathrm{C}$ at the Tasman Plateau (Fig. 1). Like the estimate by Sluijs et al. (2006), the estimate by Bijl (2009) is based on $\mathrm{TEX}_{86}$ and likely has a bias to summer temperatures. Considering the summer temperature, our simulation is still too cold by $9 \mathrm{~K}$ over the southern Pacific Ocean. 
Table 2. Simulations performed with boundary conditions for the early Eocene climate and the pre-industrial climate. The listed vegetation cover is prescribed on all ice-free continents. The values for the land surface albedo refer to snow-free regions. In the desert world, the surface albedo equals the soil albedo. In the forest world, trees cover the soil completely and the albedo of the forests determines land surface albedo.

\begin{tabular}{lll}
\hline & Vegetation & $\begin{array}{l}\text { Land } \\
\text { surface } \\
\text { albedo }\end{array}$ \\
\hline Dark desert world & none & 0.1 \\
Bright desert world & none & 0.4 \\
Forest world & $100 \%$ tree cover & 0.12 \\
\hline
\end{tabular}

The cold bias in the high latitudes is a common problem when simulating the early Eocene climate as Lunt et al. (2012) show within the Eocene Modelling Intercomparison Projects (EoMIP). In comparison to the models participating in the EoMIP, our model is within the range of other model results indicating that our background climate represents the early Eocene climate about as well as simulations from other state-of-the-art models do. Further, we seek to investigate the biogeophysical effect of vegetation in a warm, nearly ice-free background climate instead of to simulate the early Eocene as realistically as possible. Since sea ice occurs only in a few years in our simulation and snow appears only during polar night in central Antarctica and in the High North, this Eocene simulation is suitable for our purpose.

\subsection{Simulations}

Starting from our early Eocene background climate, we perform three simulations (Table 2). In the dark desert world, we replace the savanna vegetation by deserts with a soil albedo of 0.1. Similarly, no vegetation exists in the bright desert world, but this time, soil albedo is 0.4 . In the forest world, all continents are completely covered with forests. The vegetation cover is static and the leaf area index (LAI) is constant throughout the whole simulation independent of season, temperature, and water availability. We distinguish between tropical and extra-tropical trees (Fig. 2). The boundary between tropical trees and extra-tropical trees is prescribed based on the climatic limits of tropical trees computed from off-line simulations by Heinemann et al. (2009) for the Eocene climate and by Port et al. (2012) for the pre-industrial climate. Tropical trees have a LAI of 7 and a roughness length of $2 \mathrm{~m}$. Extra-tropical trees have a LAI of 5 and a roughness length of $1 \mathrm{~m}$. To facilitate comparison between the Eocene and the pre-industrial simulations, we ignore that the climatic requirements for tropical trees differ between the Eocene and the pre-industrial case. (This will be re-assessed in the last section.) The soil albedo does not matter in the forest world. This was tested by simulating the forest world climate with

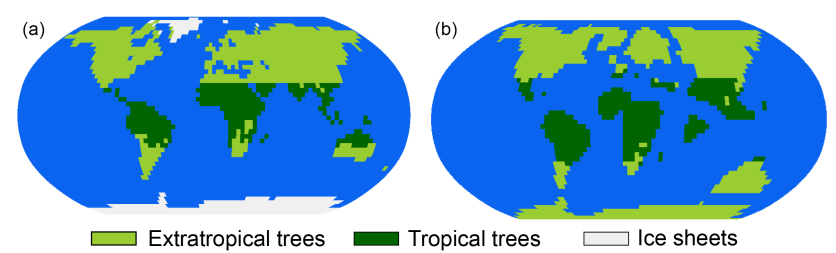

Figure 2. Vegetation cover in the forest world for the pre-industrial climate (a) and the early Eocene climate (b). Extra-tropical trees and tropical trees differ concerning their LAI and roughness length.

low and high soil albedo, respectively. Both soil albedo values yield the same climate (not shown) because trees completely mask the soil leading to a land surface albedo of approximately 0.12 in snow-free regions in the forest world.

Consistent with the Eocene simulations, we perform three simulations with pre-industrial boundary conditions. All preindustrial simulations start from the equilibrium climate by Port et al. (2012), whose pre-industrial simulation ran for 1000 years, with dynamic vegetation cover and an atmospheric $\mathrm{CO}_{2}$ concentration of about $280 \mathrm{ppm}$. In the first time step, we replace the mixed pre-industrial vegetation cover with dark desert, bright desert, and forests in the dark desert world, bright desert world, and forest world simulation, respectively. Ice sheets on Greenland and Antarctica remain unchanged.

\section{Methods}

The simulations - dark desert world, bright desert world, forest world - last for 400 years. After that period, climate has approached, but not yet reached, an equilibrium at the end of the simulations. To estimate the impact of forests on climate from these (still unequilibrated) simulations, we quantify the radiative forcing by forests and the subsequent climate feedbacks by using the linear regression approach by Gregory et al. (2004). This method has proven to be very useful to analyse radiative forcing and feedback triggered by a strong, large-scale perturbation from transient simulations. The advantage of this method is that the first decades after the perturbation are sufficient to estimate radiative forcing and feedbacks, and climate does not need to be simulated until the new equilibrium is reached.

\subsection{Estimating radiative forcing and climate feedbacks}

At the beginning of each simulation, we change the vegetation cover and the soil albedo drastically. The modification of the land surface acts as an external forcing on the climate system and perturbs the radiation balance at the top of the atmosphere (TOA). During the simulation, the perturbation in the TOA radiation balance, $\Delta R$, changes surface temperature. Temperature changes feed back to $\Delta R$ due to internal mechanisms in the climate system. In the global mean, $\Delta R$ 
relates approximately linearly to the changes in surface temperature, $\Delta T$,

$\Delta R(t)=\Delta Q+\lambda \Delta T(t)$.

The instantaneous response of the TOA radiation balance to the modification of the land surface is the radiative forcing, $\Delta Q$. The climate feedback parameter, $\lambda$, quantifies the strength of feedbacks between $\Delta T$ and $\Delta R$.

From the model simulations, we calculate global annual mean values for $\Delta R$ and $\Delta T$, and obtain pairs of $\Delta R^{i}$ and $\Delta T^{i}$ for each year, $i$. Figure 3 shows the points of $\left(\Delta T^{i}\right.$, $\Delta R^{i}$ ) for the early Eocene dark desert world simulation. In the initial equilibrium climate, savanna covers all continents but in the first year of the dark desert simulation, we replace savanna by dark bare soil. During the simulation, the simulated climate progressively approaches a new equilibrium. The straight line fitted to the points of $\left(\Delta T^{i}, \Delta R^{i}\right)$ reveals the parameters in Eq. (1) (Gregory et al., 2004). At the intersection of the regression line with the $\Delta R$ axis, $\Delta R$ is the radiative forcing $\Delta Q$. The slope of the regression line is the feedback parameter $\lambda$. Here, the regression line has a negative slope, $\lambda$, indicating that feedbacks counteract the perturbation in the TOA radiation balance. In other words, feedbacks stabilise climate.

The linear regression further allows one to estimate the equilibrium temperature change by deforestation. At the intersection of the regression line with the $\Delta T$-axis, the perturbation in TOA radiative flux becomes zero and the temperature is in a new equilibrium. The according estimated equilibrium temperature change is

$\Delta T^{\mathrm{eq}}=-\frac{\Delta Q}{\lambda}$.

Li et al. (2012) assess the question whether the Gregory method reveals a realistic estimate for the equilibrium nearsurface warming in response to a doubling of atmospheric $\mathrm{CO}_{2}$ concentration. They find that the Gregory method underestimates equilibrium warming by only $10 \%$ relative to a simulation which runs until equilibrium is reached. Their results let us assume that the Gregory method provides a reasonable estimate of the equilibrium temperature change.

The feedback parameter is evaluated from the slope of the regression line which could change with time. For the first decades after a perturbation, however, Gregory et al. (2004) find a constant slope. In line with Andrews et al. (2012), we hence consider the first 150 years of our simulation for the regression.

For the forest world simulation, the linear regression approach reveals the radiative forcing and the feedbacks by afforesting savanna-like vegetation. However, we aim to estimate the radiative forcing and the feedbacks from afforesting deserts on all continents. Hence, we modify the linear regression approach in the way that we combine the forest world simulation with the desert world simulations. Let $\Delta R_{\mathrm{d}}$

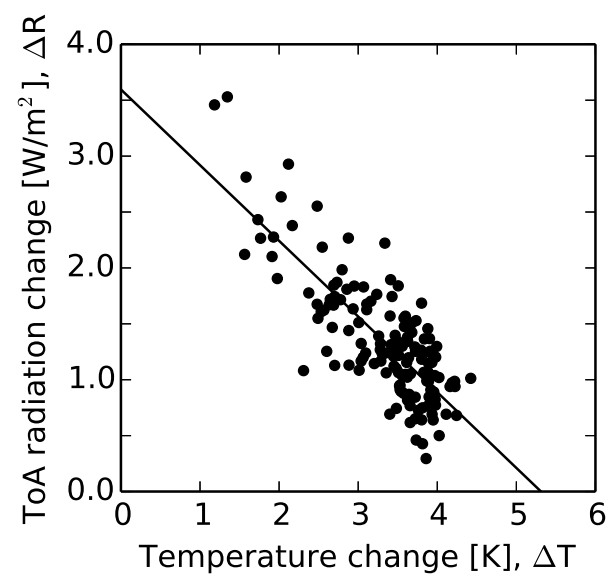

Figure 3. Evolution of radiative flux at the top of the atmosphere with temperature changes at the surface in the dark desert world of the early Eocene climate. At the beginning of the simulation, savanna-like vegetation is replaced by bare soil with an albedo of 0.1 . The first 150 simulated years are shown. The black line is the fitted regression line.

be the perturbation of the net TOA radiation in the case of replacing savanna with desert, and let $\Delta R_{\mathrm{f}}$ be the perturbation in the case of replacing savanna with forest. In the linear approach, the difference, $\Delta R_{\mathrm{fd}}$, is the perturbation due to replacing deserts by a complete forest cover. For each year in our simulation, $i$, we define

$\Delta R_{\mathrm{fd}}^{i}=\Delta R_{\mathrm{f}}^{i}-\Delta R_{\mathrm{d}}^{i}$.

Consistently, we subtract the temperature differences of the two perturbation experiments to obtain

$\Delta T_{\mathrm{fd}}^{i}=\Delta T_{\mathrm{f}}^{i}-\Delta T_{\mathrm{d}}^{i}=T_{\mathrm{f}}^{i}-T_{\mathrm{d}}^{i}$.

Considering Eq. (1), the regression line to the points $\left(\Delta T_{\mathrm{fd}}^{i}\right.$, $\left.\Delta R_{\mathrm{fd}}^{i}\right)$ is

$\Delta R_{\mathrm{fd}}=\Delta Q_{\mathrm{fd}}+\lambda_{\mathrm{fd}} \Delta T_{\mathrm{fd}}$.

The radiative forcing of afforesting the desert world is expressed by $\Delta Q_{\mathrm{fd}}$. The according feedback parameter is $\lambda_{\mathrm{fd}}$. The equilibrium temperature response, $\Delta T_{\mathrm{fd}}^{\mathrm{eq}}$, is approximated by

$\Delta T_{\mathrm{fd}}^{\mathrm{eq}}=-\frac{\Delta Q_{\mathrm{fd}}}{\lambda_{\mathrm{fd}}}$.

\subsection{Decomposition of the radiation balance}

The net perturbation in the TOA radiation balance consists of a long-wave component (LW) and a short-wave component (SW). Both components consist of a cloud share (cl) and a clear-sky share (cs) leading to

$\Delta R=\Delta R_{\mathrm{LWcl}}+\Delta R_{\mathrm{LWcs}}+\Delta R_{\mathrm{SWcl}}+\Delta R_{\mathrm{SWcs}}$. 
The clear-sky share in radiation represents the radiation when clouds are neglected. The cloud share refers to the difference between the clear-sky radiation and the all-sky radiation. We apply the linear regression technique on each of the four radiation components. The corresponding regression lines are described by

$$
\begin{aligned}
& \Delta R_{\mathrm{LWcl}}=\Delta Q_{\mathrm{LWcl}}+\lambda_{\mathrm{LWcl}} \Delta T, \\
& \Delta R_{\mathrm{LWcs}}=\Delta Q_{\mathrm{LWcs}}+\lambda_{\mathrm{LWcs}} \Delta T, \\
& \Delta R_{\mathrm{SWcl}}=\Delta Q_{\mathrm{SWcl}}+\lambda_{\mathrm{SWcl}} \Delta T, \\
& \Delta R_{\mathrm{SWcs}}=\Delta Q_{\mathrm{SWcs}}+\lambda_{\mathrm{SWcs}} \Delta T .
\end{aligned}
$$

This approach separates net radiative forcing and feedback into the single components of radiation (Andrews et al., 2012).

The long-wave clear-sky feedback parameter, $\lambda_{\mathrm{LWcs}}$, quantifies mainly the sum of the Planck feedback, the watervapour feedback, and the lapse-rate feedback. The Planck feedback refers to the modified emission of long-wave radiation when surface and troposphere change their temperature while keeping the vertical temperature gradient. For instance, a warming increases the emission of long-wave radiation by the surface leading to an energy loss at the top of the atmosphere. The energy loss counteracts the initial warming and stabilises the climate.

We estimate the Planck feedback parameter, $\lambda_{\mathrm{P}}$, as

$\lambda_{\mathrm{P}}=\frac{\partial R}{\partial T}=-4 \sigma \epsilon T^{3}$.

The term on the right-hand side consists of the StefanBoltzmann constant, $\sigma$, the global mean surface temperature in Kelvin [K], $T$, and the emissivity of the atmosphere, $\epsilon$. The emissivity describes the strength of the greenhouse effect and varies depending on the climate state. We estimate $\epsilon$ from the ratio of long-wave radiation escaping at the top of the atmosphere to long-wave radiation emitted by the surface. At the beginning of the simulations, $\epsilon$ is 0.585 and 0.541 for pre-industrial conditions and for the early Eocene climate, respectively, which reflects a stronger greenhouse effect in the warmer early Eocene climate. The corresponding global mean surface temperatures are 287 and $297 \mathrm{~K}$, respectively. Considering these values, Eq. (12) reveals a $\lambda_{P}$ of -3.1 and $-3.3 \mathrm{~W} \mathrm{~m}^{-2} \mathrm{~K}^{-1}$ for pre-industrial conditions and for the early Eocene climate, respectively. Assuming that feedbacks act linearly, we subtract $\lambda_{\mathrm{P}}$ from $\lambda_{\mathrm{LWcl}}$. The remaining feedback parameter is mainly the lapse-rate and water-vapour feedback which we name $\lambda$ WV+LR .

We quantify the uncertainty of radiative forcings and climate feedbacks in terms of the $95 \%$ confidence interval which we assess using bootstrapping. We randomly select 150 pairs of differences in temperature and TOA radiative flux out of the first 150 years of our simulation. Each pair of our simulation can be selected several times. We repeat the resampling 10000 times. From each time, we es-

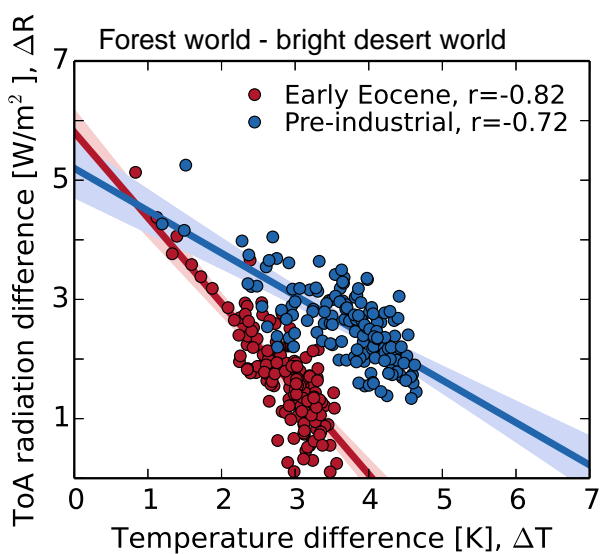

Figure 4. Evolution of differences in the TOA radiative flux between the forest world and the bright desert world with corresponding differences in near-surface temperature. Global annualmean values are considered. Red and blue points relate to the early Eocene climate and to the pre-industrial climate, respectively. The first 150 years are shown and considered for the regression and the correlation coefficient, $r$. The shaded areas refer to the $95 \%$ confidence interval for the regression lines.

timate the feedbacks and forcings. Then, we sort the resulting 10000 values. Truncating the upper and lower $2.5 \%$ provides the $95 \%$ confidence interval.

\section{Results and discussion}

\subsection{Forestation of a bright desert world}

Relative to the bright desert world, the forest world is 4.2 and $5.7 \mathrm{~K}$ warmer at the end of the early Eocene simulations and at the end of the pre-industrial simulations, respectively (Table 3). The warming results from a positive radiative forcing by trees which is 5.8 and $5.2 \mathrm{~W} \mathrm{~m}^{-2}$ for the early Eocene climate and for the pre-industrial climate. The forcings do not differ significantly at the $95 \%$ level as the confidence interval in Fig. 4 illustrates.

The largest component in net radiative forcing is the shortwave clear-sky radiative forcing, $\Delta Q_{\text {SWcs }}$, which amounts to some $15 \mathrm{~W} \mathrm{~m}^{-2}$ in both climate states (Fig. 5). The major mechanism leading to $Q_{\mathrm{SWcs}}$ is the surface albedo reduction by forest. To evaluate the surface albedo reduction, we analyse the difference in the land surface albedo between the forest world and the bright desert world in the first year of the simulations. In the first year, mainly the contrasting vegetation cover causes the difference in surface albedo because the climate response to the radiative forcing is still weak leading to negligible changes in snow cover and sea-ice cover. In the global mean, the land surface albedo is 0.26 lower in the forest world than in the bright desert world for the early Eocene climate. For pre-industrial conditions, the land surface albedo decreases by 0.28 due to forest. The strong 


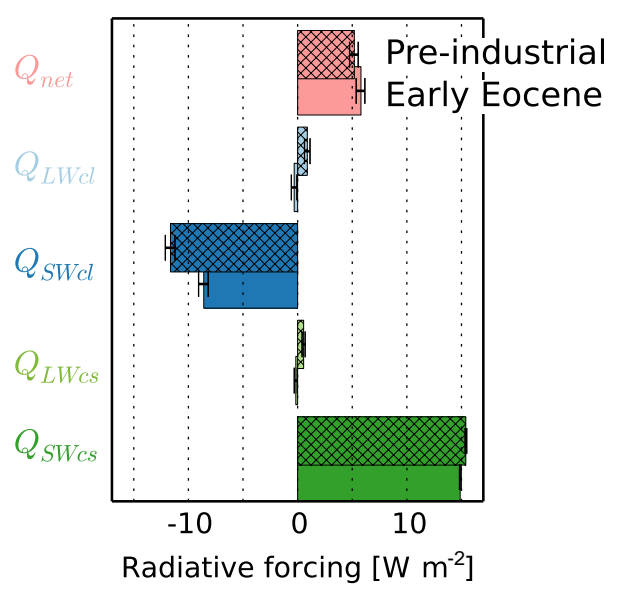

Figure 5. Net radiative forcing and its single components for the comparison of the forest world to the bright desert world. Hatched and plain bars show the radiative forcings for the pre-industrial climate and the early Eocene climate, respectively. The error bars refer to the $95 \%$ confidence interval.

albedo changes in both climate states are consistent with large values of $\Delta Q_{\text {SWcs }}$.

The second pronounced component in radiative forcing is the short-wave cloud radiative effect, $\Delta Q_{\mathrm{SWcl}}$, which amounts to -8.6 and $-11.6 \mathrm{~W} \mathrm{~m}^{-2}$ for the early Eocene climate and for the pre-industrial climate, respectively (Fig. 5). $\Delta Q_{\mathrm{SWcl}}$ describes the radiative impact of changes in cloud cover as well as an indirect impact of clouds which we define below as "masking effect". In our simulations, cloud adjustment mainly refers to an increased cloud cover due to forests leading to a higher planetary albedo and a negative radiative forcing. This effect is especially strong over land, where forests strongly reduce surface albedo and the increased cloud cover compensates the surface albedo reduction. Figure 6 illustrates the compensation of surface albedo reduction. Shown are the difference in planetary albedo and in cloud cover between the first year of the forest world simulation and the first year of the desert world simulation. In general, planetary albedo over land decreases due to forests, but in the tropics, cloud cover increases which compensates the decrease in planetary albedo.

Beside cloud adjustment, $\Delta Q_{\mathrm{SWcl}}$ includes the cloud masking effect. This effect is an artefact which results from separating full-sky radiation into the clear-sky component and the cloud component. If a dense cloud cover occurs in the forest world and in the desert world, full-sky short-wave radiative forcing will be weak. Clear-sky radiation, however, will be strongly positive due to the lower surface albedo in the forest world than in the desert world. Deriving the cloud forcing from the weak full-sky radiative forcing and the strongly positive clear-sky radiation reveals a strongly negative cloud radiative forcing even though cloud cover did not change. As $\Delta Q_{\mathrm{SWcl}}$ includes cloud adjustment and cloud masking, we can not disentangle both effects, and we can not quantify the radiative forcing by cloud adjustment alone.

Feedbacks stabilising the climate are stronger for the early Eocene climate than for the pre-industrial case as the steeper slope of the regression line in Fig. 4 illustrates. Stronger stabilising feedbacks lead to a weaker warming by forests at the end of the Eocene simulation (Table 3) and to a smaller estimated equilibrium temperature response than for preindustrial conditions. This result is surprising because the simulations by Caballero and Huber (2013) indicate the opposite result. They analyse the strength of feedbacks triggered by a greenhouse gas forcing for different climate states. The study shows that feedbacks stabilise a warmer climate less than a colder climate leading to a higher climate sensitivity in the warmer climate. Presumably, the feedbacks associated with a response to an increase in greenhouse gas concentration cannot directly be compared with feedbacks arising from a response to changes in land surface.

We analyse the single components of the net feedback to identify the reason for the different strengths in net feedback in both climate states. The short-wave clear-sky feedback parameter, $\lambda_{\mathrm{SW} s}$, is significantly smaller for the early Eocene climate than for pre-industrial conditions (Fig. 7). This feedback mainly refers to changes in the sea-ice cover and snow cover together with the short-wave contribution of the watervapour feedback. We expect that the ice-albedo feedback is weak for the early Eocene climate because permanent sea-ice is absent and snow occurs only seasonally. The small $\lambda_{\text {SWcs }}$ agrees with this expectation. Also the zonal mean temperature difference between the forest world and the desert world indicates a weak ice-albedo feedback because forests warm the northern high latitudes much less for the early Eocene climate than they do for pre-industrial conditions (Fig. 8).

$\lambda \mathrm{WV}+\mathrm{LR}$ largely quantifies the sum of the negative lapserate feedback and the positive water-vapour feedback. This feedback parameter is larger for the early Eocene climate than for pre-industrial conditions indicating either a weaker lapse-rate feedback, a stronger water-vapour feedback, or both. This result agrees with previous studies which find that the water-vapour feedback is stronger the warmer the climate is (Meraner et al., 2013; Loptson et al., 2014).

The largest differences in the feedback parameters appear in the short-wave cloud feedback parameter, $\lambda_{\mathrm{sWcl}}$, which is $-0.8 \mathrm{~W} \mathrm{~m}^{-2} \mathrm{~K}^{-1}$ for the early Eocene climate and $0.1 \mathrm{~W} \mathrm{~m}^{-2} \mathrm{~K}^{-1}$ for the pre-industrial climate. Even considering the large uncertainty in the estimate, $\lambda_{\mathrm{SWcl}}$ differs significantly between the early Eocene and pre-industrial conditions. The cloud albedo feedback is stronger and of opposite sign for the early Eocene climate than for pre-industrial conditions. $\lambda_{\mathrm{SWcl}}$, however, also includes masking effects of clouds which weakens the result on the climate-dependent cloud albedo feedback.

To identify the reason for the different sign in $\lambda_{\mathrm{SWcl}}$ for the cold and warm climates considered here, we analyse $\lambda_{\mathrm{SWcl}}$ in further detail. We separate the difference in the short-wave 
Table 3. Net radiative forcing by afforesting a bright desert world for the early Eocene climate and the pre-industrial climate. Further, the net feedback parameter and the equilibrium temperature change are listed. The values are derived from the comparison of the respective forest world with the respective bright desert world using the linear regression approach (Sect. 3.1). The estimated equilibrium temperature change is based on Eq. (6). The $95 \%$ confidence interval is given. The transient temperature change refers to the temperature difference averaged over the last 30 years of the simulations.

\begin{tabular}{lll}
\hline & Early Eocene & Pre-industrial \\
\hline Radiative forcing $\left[\mathrm{W} \mathrm{m}^{-2}\right]$ & $5.8 \pm 0.4$ & $5.2 \pm 0.5$ \\
Feedback parameter $\left[\mathrm{W} \mathrm{m}^{-2} \mathrm{~K}^{-1}\right]$ & $-1.4 \pm 0.1$ & $-0.7 \pm 0.1$ \\
Estimated equilibrium temperature change [K] & $4.1 \pm 0.1$ & $7.3 \pm 0.7$ \\
Temperature change at the end of the simulations $[\mathrm{K}]$ & 4.2 & 5.7 \\
\hline
\end{tabular}

(a)

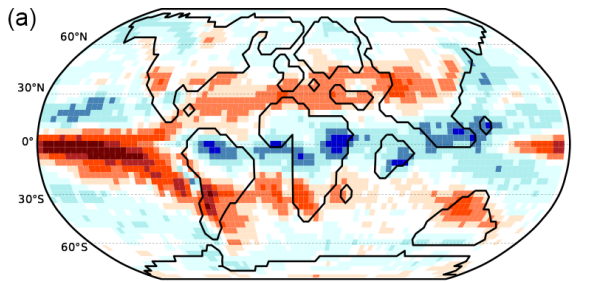

(b)

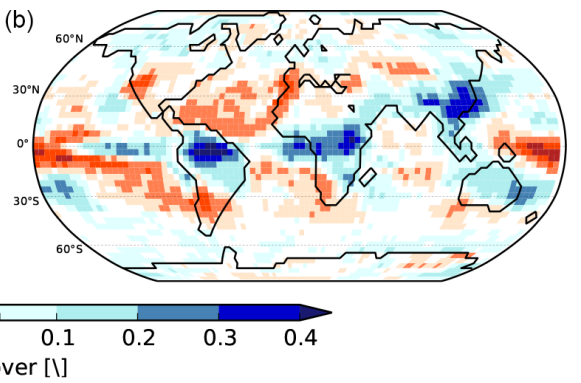

(c)

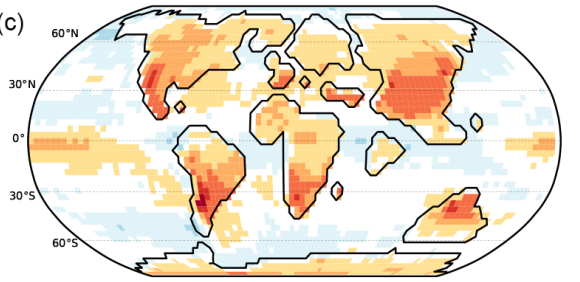

(d)

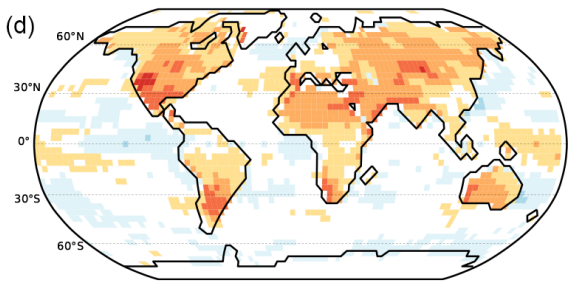

$\begin{array}{lllllll}-0.25-0.20-0.15-0.10 & -0.03 & 0.03 & 0.10 & 0.15 & 0.20 & 0.25\end{array}$

$\Delta$ Planetary albedo [ $\mathrm{I}]$

Figure 6. Difference in cloud cover and planetary albedo between the forest world and the bright desert world averaged over the first year of the simulations. Differences in planetary albedo result from differences in surface albedo and in cloud cover. (a, c) show the differences for the early Eocene climate and $(\mathbf{b}, \mathbf{d})$ for the pre-industrial climate.

cloud radiative flux between the forest world and the bright desert world, $\Delta R_{\mathrm{SWcl}}$, into $\Delta R_{\mathrm{SWcl}}$ above oceans and above continents (similar to Andrews et al., 2012). We display temperature differences over continents with radiation differences over continents (Fig. 9a). Similarly, we display temperature differences over oceans with radiation differences over oceans (Fig. 9b).

Over the continents, $\lambda_{\mathrm{SWcl}}$ is nearly of the same strength in both climate states as the slopes of the regression lines in Fig. 9a illustrate. Over the oceans, however, $\lambda_{\mathrm{SWcl}}$ is positive for pre-industrial conditions and negative for the early Eocene climate (Fig. 9b). The opposite sign in $\lambda_{\mathrm{SWcl}}$ over the ocean indicates that presumably, a different structure in cloud cover changes in both climates (see Fig. 6) is the reason for a state-dependent cloud feedback in our simulations.

A state-dependent cloud feedback is also suggested by Goldner et al. (2013) who estimate the climate sensitivity to the Antarctic ice sheet in today's climate and in the
Eocene climate. Their simulations suggest that the Antarctic ice sheet cools both climates. Changes in low clouds amplify the cooling in the Eocene climate, while changes in low clouds dampen the cooling in modern climate. Despite the agreement with Goldner et al. (2013), we have to interpret our results with caution because cloud feedbacks are highly model-dependent (Randall et al., 2007; Dufresne and Bony, 2008). As a further word of caution, we should remember that the Gregory approach includes the assumption that feedbacks act linearly. Figure 9b, however, indicates that the TOA cloud short-wave radiation seems to evolve non-linearly with temperature in the early Eocene. We are currently not able to explain this behaviour.

\subsection{Forestation of a dark desert world}

In the dark desert world, soils have about the same albedo as forests. Nonetheless, forests reduce temperature by 4.2 and 
Table 4. Net radiative forcing by afforesting a dark desert world for the early Eocene climate and for pre-industrial conditions. Further, the net feedback parameter and the equilibrium temperature change are listed. The values are derived from the comparison of the respective forest world with the respective dark desert world using the linear regression approach (Sect. 3.1). The estimated equilibrium temperature change is based on Eq. (6). The $95 \%$ confidence interval is given. The temperature change at the end on the simulations considers the average over the last 30 years of the simulation.

\begin{tabular}{lll}
\hline & Early Eocene & Pre-industrial \\
\hline Radiative forcing $\left[\mathrm{W} \mathrm{m}^{-2}\right.$ ] & $-3.4 \pm 0.4$ & $-3.1 \pm 0.5$ \\
Feedback parameter $\left[\mathrm{W} \mathrm{m}^{-2} \mathrm{~K}^{-1}\right.$ ] & $-0.7 \pm 0.1$ & $-0.8 \pm 0.2$ \\
Estimated equilibrium temperature change $[\mathrm{K}]$ & $-5.3 \pm 0.6$ & $-3.8 \pm 0.5$ \\
Temperature change at the end of the simulations $[\mathrm{K}]$ & -4.2 & -3.0 \\
\hline
\end{tabular}

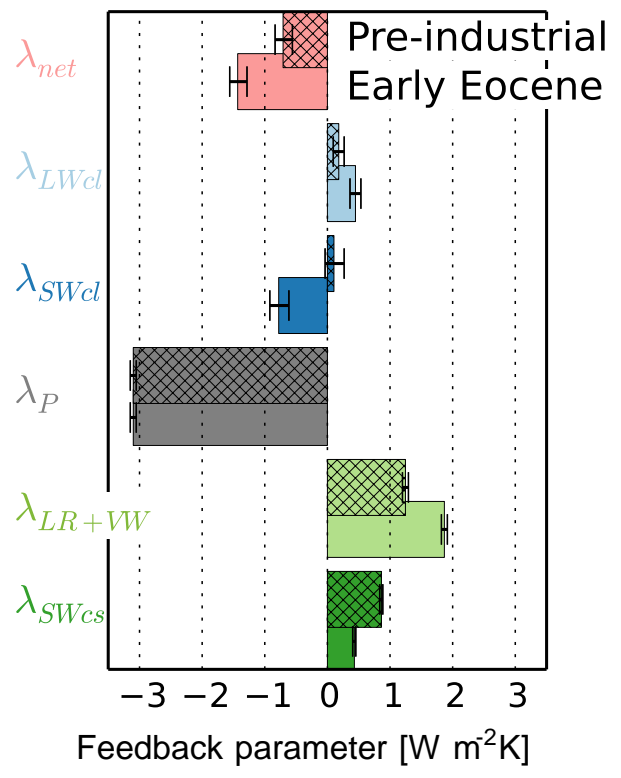

Figure 7. Net feedback parameter and its single components for the comparison of the forest world to the bright desert world. Hatched and plain bars show the feedback parameters for the pre-industrial climate and the early Eocene climate, respectively. The error bars refer to the $95 \%$ confidence interval.

3.0 K until the end of the early Eocene simulations and until the end of the pre-industrial simulations, respectively (Table 4). The cooling results from a negative radiative forcing of about $3 \mathrm{~W} \mathrm{~m}^{-2}$ in both climate states (Fig. 10). The main contributor to the net radiative forcing is the short-wave cloud component $\Delta Q_{\mathrm{SWcl}}$ (Fig. 11) which amounts to about $-5 \mathrm{~W} \mathrm{~m}^{-2}$ in both climates. The negative $\Delta Q_{\mathrm{sWcl}}$ illustrates that forests cool the dark desert world by increasing cloud cover.

The individual feedbacks are of different strengths for the early Eocene climate and for pre-industrial conditions (Fig. 12). The combined lapse-rate and water-vapour feedback, $\lambda_{\mathrm{LR}+\mathrm{VW}}$, is larger for the early Eocene climate than for pre-industrial conditions, while the short-wave clear-sky component, $\lambda_{\mathrm{SWcs}}$, is smaller for the early Eocene climate. The larger $\lambda_{\mathrm{LR}+\mathrm{VW}}$ for the early Eocene climate indicates

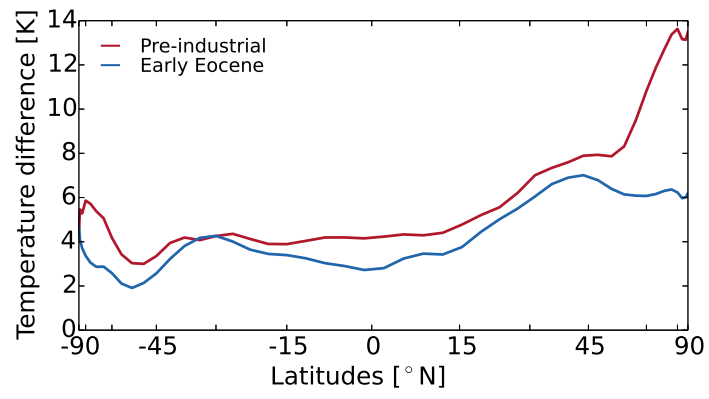

Figure 8. Zonal mean temperature difference between the forest world and the desert world. Red line and blue line refer to the early Eocene climate and the pre-industrial climate, respectively. The average over the last 30 years of the simulation is considered.

a stronger lapse-rate and water-vapour feedback which amplifies the cooling by forests on a global scale. The smaller $\lambda_{\text {SWcs }}$ can likely be attributed to a weaker sea-ice albedo feedback which leads to a weaker polar amplification of the cooling by forests than for pre-industrial conditions.

\section{Conclusions}

We have compared the biogeophysical effect of forests in a warm, nearly ice-free climate and in a cool climate with permanent ice-cover at high latitudes. To this end, we have chosen simulations of the early Eocene climate and the preindustrial climate. We have separated the effect of forests in the radiative forcing and the feedbacks induced by implementing a forest cover on desert continents. To assess the sensitivity of our results to the soil albedo, we have assumed either a high soil albedo or a low soil albedo. When soils have a much higher albedo than the forest cover, we find a positive radiative forcing by forests in the current interglacial climate. Our analysis reveals that the major cause is the surface albedo reduction by forests which is partly offset by an increased cloud cover by forests leading to a higher planetary albedo. The positive net radiative forcing results in a global warming and induces climate feedbacks: the lapse-rate - water-vapour and cloud feedbacks enhance warming on a global scale; and 

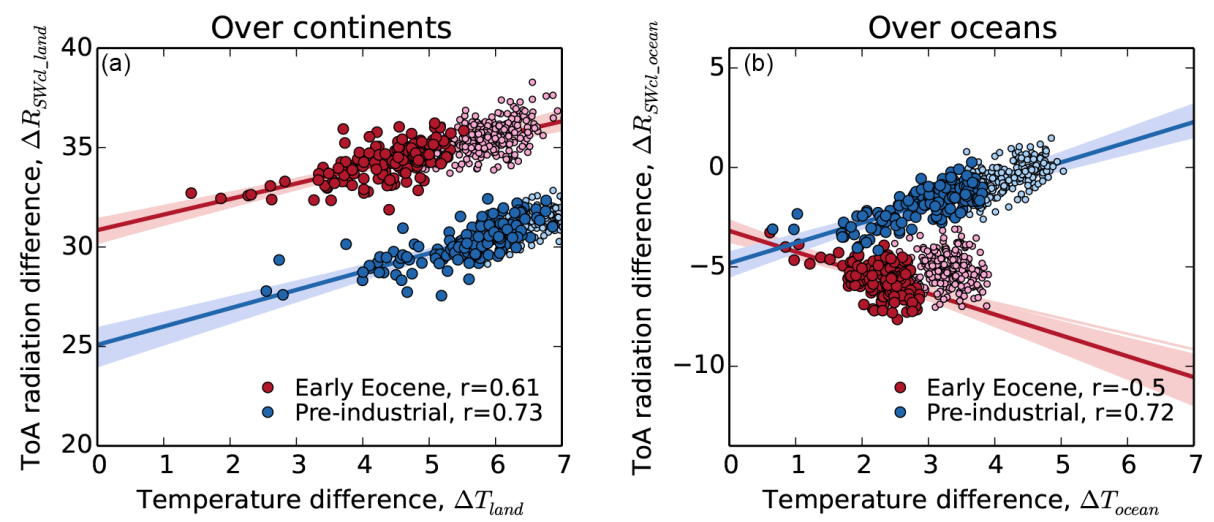

Figure 9. Evolution of the difference in TOA short-wave cloud radiative flux, $R_{\mathrm{SWcl}}$, with differences in near-surface temperature between the forest world and the bright desert world. The evolution of $R_{\mathrm{SWcl}}$ is separated in the evolution above the continents (a) and above the oceans (b). Global annual-mean values are considered. Red and blue points relate to the early Eocene climate and to the pre-industrial climate, respectively. Dark large points and bright small points show the first 150 years and the last 250 years, respectively. The regression and the correlation coefficient, $r$, consider the first 150 years. The shaded areas refer to the $95 \%$ confidence interval for the regression lines.

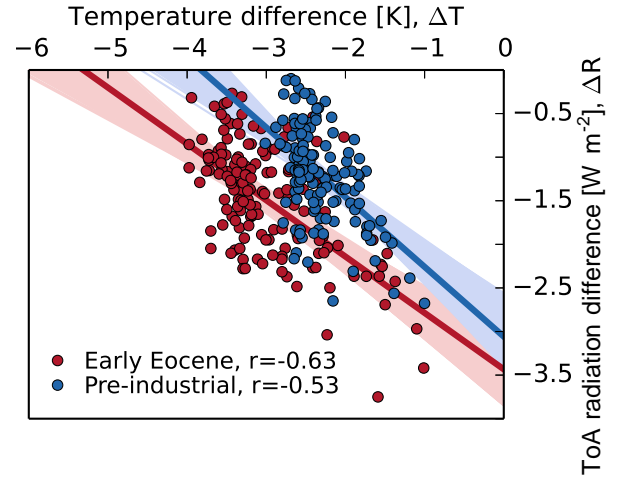

Figure 10. Evolution of differences in the TOA radiative flux between the forest world and the dark desert world with corresponding temperature differences. Global annual mean values are considered. Red and blue points relate to the early Eocene climate and to the pre-industrial climate, respectively. The first 150 years are shown and considered for the regression and the correlation coefficient, $r$. The shaded areas refer to the $95 \%$ confidence interval for the regression lines.

the sea-ice albedo feedback amplifies warming in the northern high latitudes.

In the nearly ice-free, warm climate of the early Eocene, we find a similar radiative forcing by forests as in the preindustrial interglacial climate. Climate feedbacks, however, differ considerably. The sea-ice albedo feedback is weaker for the early Eocene climate than for the pre-industrial climate leading to a weaker warming by forests in the northern high latitudes. The positive lapse-rate and water-vapour feedback is stronger than for pre-industrial conditions. Negative cloud-related feedbacks, however, are also stronger than for pre-industrial conditions and nearly outweigh the stronger positive lapse-rate and water-vapour feedback. In total, cli-

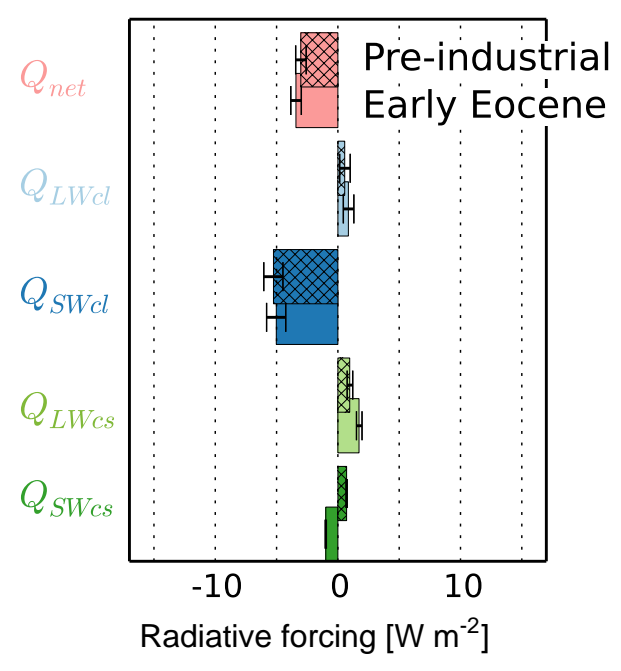

Figure 11. Net radiative forcing and its single components for the comparison of the forest world to the dark desert world. The hatched and the plain bars show the radiative forcings for the pre-industrial climate and the early Eocene climate, respectively. The error bars refer to the $95 \%$ confidence interval.

mate feedbacks stabilising the global climate are stronger for the early Eocene climate than for the pre-industrial case, and forests warm the Eocene climate to a lesser degree than the pre-industrial climate.

If soils have an albedo close to the albedo of the forest cover, then our simulations suggest that forests cool the climates by enhancing cloud cover leading to an increased planetary albedo. Like in the bright soil case, the corresponding radiative forcing is equally strong for the early Eocene climate as for pre-industrial conditions, but the triggered climate feedbacks differ leading to a different amount of cooling: a stronger positive lapse-rate and water-vapour feedback 


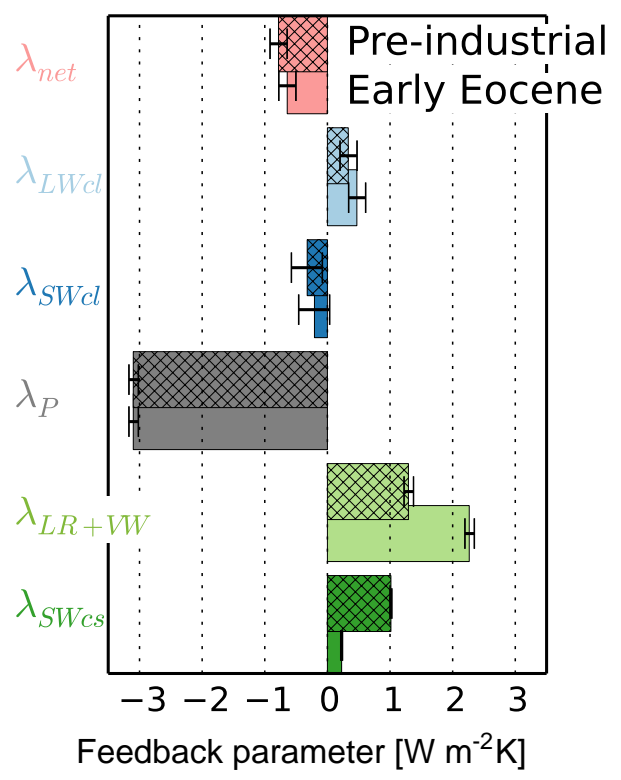

Figure 12. Net feedback parameter and its single components for the comparison of the forest world to the dark desert world. The hatched and the plain bars show the feedback parameters for the pre-industrial climate and the early Eocene climate, respectively. The error bars refer to the $95 \%$ confidence interval.

for the early Eocene climate results in a stronger global cooling than in pre-industrial climate, and a much weaker snow and ice-albedo feedback leads to a weaker high-latitude cooling for the early Eocene climate than for pre-industrial conditions.

In the real world, the values of surface albedo are within the range of the values prescribed in our sensitivity study. In most regions the surface albedo is much closer to the low value of 0.1 than to the high value. Only in some desert regions with desiccated palaeo lakes, like the Bodélé depression in North Africa today, values are as high as 0.4 . We assume that this is valid also for the Early Eocene climate. Therefore, we assume that our results for dark soil are applicable to the real world qualitatively albeit with a smaller amplitude of values.

Even though we have presented results from only one model, we assume that our main conclusion - that radiative forcing varies little with the climate state, while subsequent feedbacks depend on the climate state - is valid in general. A weak snow/ice albedo feedback in an almost ice-free climate is what we expect other models to reproduce. A stronger water-vapour feedback in a warmer climate is consistent with previous studies using another model (Loptson et al., 2014). Our results on cloud feedbacks, however, are likely modeldependent because cloud feedbacks differ among models in general (Randall et al., 2007; Dufresne and Bony, 2008).

In our study, plant functional types are considered to be the same for the early Eocene climate as for the pre-industrial climate. We assume that this simplification will only weakly affect the results of our study, at least in the qualitative sense. We prescribe extreme land cover differences between completely forested and completely deserted continents. This difference presumably causes much stronger effects than the difference in the physiology between current forests and early Eocene forests. The topic of changing plant functional types with climate will be subject to further studies.

Acknowledgements. We are grateful for comments by Bjorn Stevens and Thorsten Mauritsen, and we thank Veronika Gayler and Helmuth Haak for technical support. Comments by two anonymous reviewers which improved this paper are greatly appreciated. This work used computational resources by Deutsches Klima Rechenzentrum (DKRZ) and was supported by the Max Planck Gesellschaft (MPG).

The article processing charges for this open-access publication were covered by the Max Planck Society.

Edited by: M. Crucifix

\section{References}

Alkama, R., Kagayama, M., and Ramstein, G.: A sensitivity study to global desertification in cold and warm climates: Results from IPSL OAGCM model, Clim. Dynam., 38, 1629-1647, doi:10.1007/s00382-011-1101-6, 2012.

Andrews, T., Gregory, J., Webb, M., and Taylor, K.: Forcing, feedbacks and climate sensitivity in CMIP5 coupled atmosphereocean climate models, Geophys. Res. Lett., 39, L09712, doi:10.1029/2012GL051607, 2012.

Bathiany, S., Claussen, M., Brovkin, V., Raddatz, T., and Gayler, V.: Combined biogeophysical and biogeochemical effects of largescale forest cover changes in the MPI earth system model, Biogeosciences, 7, 1383-1399, doi:10.5194/bg-7-1383-2010, 2010.

Beerling, D. and Royer, D.: Convergent Cenozoic $\mathrm{CO}_{2}$ history, Nat. Geosci., 4, 418-420, doi:10.1038/ngeo1186, 2011.

Betts, A. K. and Ball, J. H.: Albedo over the boreal forest, J. Geophys. Res.-Atmos., 102, 28901-28909, doi:10.1029/96JD03876, 1997.

Bice, K. L. and Marotzke, J.: Numerical evidence against reversed thermohaline circulation in the warm Paleocene/Eocene ocean, J. Geophys. Res., 106, 11529-11542, 2001.

Bijl, P. K.: Early Palaeogene temperature evolution of the southwest Pacific Ocean, Nature, 461, 776-779, doi:10.1038/nature08399, 2009.

Bonan, G. B.: Effects of boreal forest vegetation on global climate, Nature, 359, 716-718, 1992.

Bonan, G. B.: Forests and Climate Change: Forcings, Feedbacks, and the Climate Benefits of Forests, Science, 320, 1444-1449, 2008.

Brovkin, V., Raddatz, T., and Reick, C. H.: Global biogeophysical interactions between forest and climate, Geophys. Res. Lett., 36, L07405, doi:10.1029/2009GL037543, 2009. 
Caballero, R. and Huber, M.: State-dependent climate sensitivity in past warm climates and its implications for future climate projections, P. Natl. Acad. Sci. USA, 110, 14162-14167, doi:10.1073/pnas.1303365110, 2013.

Claussen, M., Brovkin, V., and Ganopolski, A.: Biogeophysical versus biogeochemical feedbacks of large-scale land cover change, Geophys. Res. Lett., 28, 1011-1014, 2001.

Dufresne, J. and Bony, S.: An Assessment of the Primary Sources of Spread of Global Warming Estimates from Coupled Atmosphere-Ocean Models, J. Climate, 21, 5135-5144, 2008.

Fraedrich, K., Jansen, H., Kirk, E., and Lunkeit, F.: The Planet Simulator: Green planet and desert world, Meteorol. Z., 14, 305-314, doi:10.1127/0941-2948/2005/0044, 2005.

Goldner, A., Huber, M., and Caballero, R.: Does Antarctic glaciation cool the world?, Clim. Past, 9, 173-189, doi:10.5194/cp-9173-2013, 2013.

Gregory, J., Ingram, W., Palmer, M., Jones, G., and Stott, P.: A new method for diagnosing radiative forcing and climate sensitivity, Geophys. Res. Lett., 31, L03205, doi:10.1029/2003GL018747, 2004.

Heinemann, M., Jungclaus, J. H., and Marotzke, J.: Warm Paleocene/Eocene climate as simulated in ECHAM5/MPI-OM, Clim. Past, 5, 785-802, doi:10.5194/cp-5-785-2009, 2009.

Huber, M. and Caballero, R.: The early Eocene equable climate problem revisited, Clim. Past, 7, 603-633, doi:10.5194/cp-7603-2011, 2011.

Hutchison, J.: Turtle, crocodilian, and champsosaur diversity changes in the Cenozoic of the north-central region of western United States, Palaeogeogr. Palaeocl., 37, 149-164, doi:10.1016/0031-0182(82)90037-2, 1982.

Ilyina, T., Six, K. D., Segschneider, J., Maier-Reimer, E., Li, H., and Nunez-Riboni, I.: Global ocean biogeochemistry model HAMOCC: Model architecture and performance as component of the MPI-Earth System Model in different CMIP5 experimental realizations, J. Adv. Model. Earth Syst., 5, 287-315, doi:10.1029/2012MS000178, 2013.

Ivany, L., Simaeys, S. V., Domack, E., and Samson, S.: Evidence for an earliest Oligocene ice sheet on the Antarctic Peninsula, Geology, 34, 377-380, doi:10.1130/G22383.1, 2006.

Jungclaus, J. H., Fischer, N., Haak, H., Lohmann, K., Marotzke, J., Matei, D., Mikolajewicz, U., Notz, D., and von Storch, J. S.: Characteristics of the ocean simulations in the Max Planck Institute Ocean Model (MPIOM) the ocean component of the MPIEarth system model, J. Adv. Model. Earth Syst., 5, 422-446, doi:10.1002/jame.20023, 2013.

Li, C., von Storch, J.-S., and Marotzke, J.: Deep-ocean heat uptake and equilibrium climate response, Clim. Dynam., 40, 10711086, doi:10.1007/s00382-012-1350-z, 2012.

Liakka, J., Colleoni, F., Ahrens, B., and Hickler, T.: The impact of climate-vegetation interactions on the onset of the Antarctic ice sheet, Geophys. Res. Lett., 41, 1269-1276, doi:10.1002/2013GL058994, 2014.

Loptson, C. A., Lunt, D. J., and Francis, J. E.: Investigating vegetation-climate feedbacks during the early Eocene, Clim. Past, 10, 419-436, doi:10.5194/cp-10-419-2014, 2014.
Lunt, D. J., Jones, T. D., Heinemann, M., Huber, M., LeGrande, A., Winguth, A., Loptson, C., Marotzke, J., Roberts, C. D., Tindall, J., Valdes, P., and Winguth, C.: A model-data comparison for a multi-model ensemble of early Eocene atmosphere-ocean simulations: EoMIP, Clim. Past, 8, 1717-1736, doi:10.5194/cp8-1717-2012, 2012.

Markwick, P.: Equability, continentality, and tertiary climate - the crocodilian perspective, Geology, 22, 613-616, doi:10.1130/0091-7613(1994)022<0613:ECATCT>2.3.CO;2, 1994.

Meraner, K., Mauritsen, T., and Voigt, A.: Robust increase in equilibrium climate sensitivity under global warming, Geophys. Res. Lett., 40, 5944-5948, doi:10.1002/2013GL058118, 2013.

Otto-Bliesner, B. L. and Upchurch, G. R.: Vegetation-induced warming of high-latitude regions during the late Cretaceous period, Nature, 385, 804-807, 1997.

Pearson, P., van Dongen, B., Nicholas, C., Pancost, R., and Schouten, S.: Stable warm tropical climate through the Eocene Epoch, Geology, 35, 211-214, 2007.

Port, U., Brovkin, V., and Claussen, M.: The influence of vegetation dynamics on anthropogenic climate change, Earth Syst. Dynam., 3, 233-243, doi:10.5194/esd-3-233-2012, 2012.

Raddatz, T. J., Reick, C. H., Knorr, W., Kattge, J., Roeckner, E., Schnur, R., Schnitzler, K.-G., Wetzel, P., and Jungclaus, J.: Will the tropical land biosphere dominate the climate-carbon cycle feedback during the twenty-first century?, Clim. Dynam., 29, 565-574, 2007.

Randall, D. A., Wood, R. A., Bony, S., Colman, R., Fichefet, T., Fyfe, J., Kattsov, V., Pitman, A., Shukla, J., Srinivasan, J., Stouffer, R. J., Sumi, A., and Taylor, K. E.: Climate models and their evaluation, in: Climate change 2007: The physical basics. Contribution of working group I to the Fourth Assessment Report of the Intergovernmental Panel on Climate Change, Cambridge University Press, Cambridge, UK and New York, NY, USA, 589-662, 2007.

Reick, C. H., Raddatz, T., Brovkin, V., and Gayler, V.: Representation of natural and anthropogenic land cover change in MPI-ESM, J. Adv. Model. Earth Syst., 5, 459-482, doi:10.1002/jame.20022, 2013.

Sewall, J. O., Sloan, L. C., Huber, M., and Wing, S.: Climate sensitivity to changes in land surface characteristics, Global Planet. Change, 26, 445-465, 2000.

Sluijs, A., Schouten, S., Pagani, M., Woltering, M., Brinkhuis, H., Sinninghe Damste, J. S., Dickens, G. R., Huber, M., Reichart, G., Stein, R., Matthiessen, J., Lourens, L. J., Pedentchouk, N., Backman, J., Moran, K., and the Expedition 302 Scientists: Subtropical Arctic Ocean temperatures during the Palaeocene/Eocene thermal maximum, Nature, 441, 610-613, 2006.

Stevens, B., Giorgetta, M., Esch, M., Mauritsen, T., Crueger, T., Rast, S., Salzmann, M., Schmidt, H., Bader, J., Block, K., Brokopf, R., Fast, I., Kinne, S., Kornblueh, L., Lohmann, U., Pincus, R., Reichler, T., and Roeckner, E.: Atmospheric component of the MPI-M Earth System Model: ECHAM6, J. Adv. Model. Earth Syst., 5, 146-172, doi:10.1002/jame.20015, 2013.

Warner, T. T.: Desert Meteorology, Cambridge University Press, 266-267, 2004. 
Wilf, P.: When are leaves good thermometers? A new case for leaf margin analysis, Paleobiology, 23, 373-390, 1997.

Wolfe, J.: Paleoclimatic estimates from Tertiary leaf assemblages, Annu. Rev. Earth Planet Sci., 23, 119-142, 1995.

Zachos, J., Berza, J., and Wise, S.: Early Oligocene icesheet expansion on Antarctica - Stable isotope and sedimentological evidence from Kerguelen Plateau southern Indian-Ocean, Geology, 20, 569-573, doi:10.1130/00917613(1992)020<0569:EOISEO>2.3.CO;2, 1992.
Zachos, J., Pagani, M., Sloan, L., Thomas, E., and Billups, K.: Trends, rhythms, and aberrations in global climate $65 \mathrm{Ma}$ to present, Science, 292, 686-693, 2001. 